\title{
Prediction of Dissolved Oxygen in Indian Sundarbans: Vision 2050
}

\author{
Gahul Amin ${ }^{1}$, Sujoy Biswas ${ }^{2}$, Sufia Zaman ${ }^{3}$, Prosenjit Pramanick ${ }^{3}$, Subrata Trivedi ${ }^{4}$ and Abhijit Mitra $^{5}$ \\ Department of Physics, Netaji Subhas Open University (Kalyani Campus), Kalyani, India ${ }^{1}$ \\ Department of Civil Engineering, Techno India University, Salt Lake Campus, Kolkata, India ${ }^{2}$ \\ Department of Oceanography, Techno India University, Salt Lake Campus, Kolkata, India ${ }^{3}$ \\ Department of Biology, Faculty of Science, University of Tabuk, Kingdom of Saudi Arabia ${ }^{4}$ \\ Department of Marine Science, University of Calcutta, Kolkata, India ${ }^{5}$
}

\begin{abstract}
Forecasting/prediction considering three decade baseline data on dissolved oxygen (DO) in western and central Indian Sundarbans reveals the probable occurrence of hypoxia in the aquatic system of this World Heritage site during 2050. Starting from the baseline year 1984 a decreasing trend of DO is observed irrespective of seasons and stations. The sudden rise of DO during premonsoon 2009 is the effect of Aila, a super-cyclone that hit the study area with a speed around $110 \mathrm{~km} / \mathrm{hr}$. Forecast value during 2050 premonsoon, monsoon and postmonsoon are 3.80 ppm, $6.08 \mathrm{ppm}, 5.55 \mathrm{ppm}$ respectively at Sagar South, whereas at Gosaba, the values are $3.25 \mathrm{ppm}, 4.63 \mathrm{ppm}$ and $3.85 \mathrm{ppm}$ during premonsoon, monsoon and postmonsoon respectively. The overall result suggests a picture of concern as the aquatic system is gradually approaching towards hypoxia. The super-cyclone Aila caused a massive adverse impact on the salinity profile of the study area as well as on the livelihood, but a congenial situation is observed with respect to DO level in the estuarine waters.
\end{abstract}

Key words: Forecast, dissolved oxygen (DO), hypoxia, Aila.

\section{INTRODUCTION}

The occurrence of severe oxygen depletion, either hypoxia ( $<2$ milligrams of oxygen per liter, or $<3 \mathrm{mg} / \mathrm{l}$ in some systems) or anoxia $(0 \mathrm{mg} / \mathrm{l})$, is a growing concern for the estuarine and coastal waters. Prolonged oxygen depletion not only can disrupt benthic and demersal communities, but also can cause mass mortalities of aquatic life (Diaz and Rosenberg, 1995). Among other problems, the consequences to coastal commercial fisheries can be disastrous (Baden et al., 1990; Zaitsev, 1991, 1993).

Oxygen depletion results from the combination of several physical and biological processes. Many estuarine and coastal systems have a natural propensity for oxygen depletion due to their basin morphology, estuarine circulation, residence time of water and high freshwater discharge. Added to these factors is the cumulative load of point source inputs of organics and nutrients, as well as more diffuse inputs of nutrients from non-point sources associated with the freshwater influx.

The nutrients delivered to estuarine and coastal systems support biological productivity. Excessive levels of nutrients, however, can cause intense biological productivity that depletes oxygen. The remains of algal blooms and zooplankton fecal pellets sink to the lower water column and the seabed. The rate of depletion of oxygen during processes that decompose the fluxed organic matter exceeds the rate of production and resupply from the surface waters. Following a fairly predictable annual cycle, oxygen depletion becomes most widespread, persistent and severe during the summer months.
In the present study we aim to evaluate the probable magnitude of hypoxia in two sampling stations located in the western and central Indian Sundarbans based on the real time data set of more than three decades (1984-2015). The data bank also encompasses the DO level during premonsoon 2009, when the super-cyclone Aila caused a sudden rise in the DO level due to turbulence in the aquatic phase.

\section{MATERIALS AND METHODS}

The entire prediction on DO level in the coming three decades (more specifically in 2050) stands on the secondary data collected since 1984. More than three decades of real time data (1984-2015) were compiled from the archives of the Department of Marine Science, University of Calcutta.

A number of studies on different aspects of Indian Sundarbans have been published over the years, which include description of the data (and methods) at different times for more than three decades (Chakraborty and Choudhury, 1985; Mitra et al., 1987; Mitra et al., 1992; Mitra and Choudhury, 1994; Saha et al., 1999; Banerjee et al., 2002; Banerjee et al., 2003; Mondal et al., 2006; Mitra et al., 2009; Mitra, 2013; Banerjee et al., 2013; Sengupta et al., 2013; Mitra and Zaman, 2014; Mitra and Zaman, 2015). Time series analysis was performed to forecast the trend of DO on the basis of the past 30 years' real-time data. Exponential smoothing method produces maximumlikelihood estimates and has been used to reflect the future trend of DO to visualize the status in 2050 . 


\section{RESULTS}

The spatial order of surface water DO during the study period is Sagar South (in western Indian Sundarbans) > Gosaba (in central Indian Sundarbans). The average values of DO in Sagar South (considering the real time data during 1984-2015) are $4.36 \mathrm{ppm}$ during premonsoon, 5.05 ppm during monsoon and 4.69 during postmonsoon. For the same period, the average values in Gosaba are 3.82 ppm during premonsoon, $4.56 \mathrm{ppm}$ during monsoon and $4.15 \mathrm{ppm}$ during postmonsoon. The data reflects the seasonal order of DO in the sequence monsoon > postmonsoon > premonsoon. The forecast method predicts the average DO values to be $3.80 \mathrm{ppm}$ and $3.25 \mathrm{ppm}$ in premonsoon, $6.08 \mathrm{ppm}$ and $4.64 \mathrm{ppm}$ in monsoon and 5.55 ppm and $3.85 \mathrm{ppm}$ in postmonsoon at Sagar South and Gosaba respectively during 2050 (Figures 1-6).

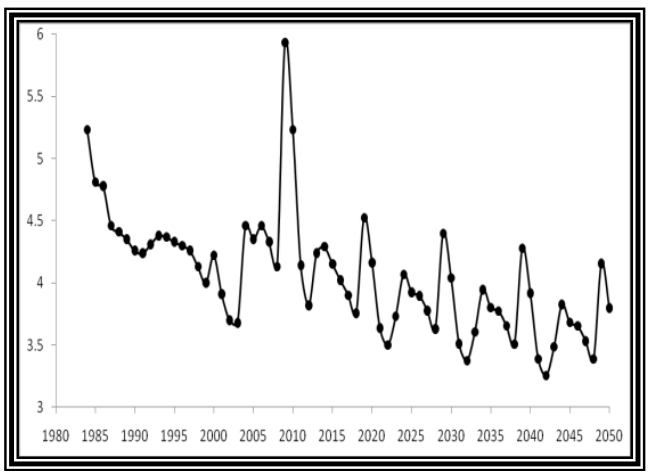

Figure 1: Temporal variation of DO real time data (1984-2015) and forecast data (2016-2050) during premonsoon at Sagar South

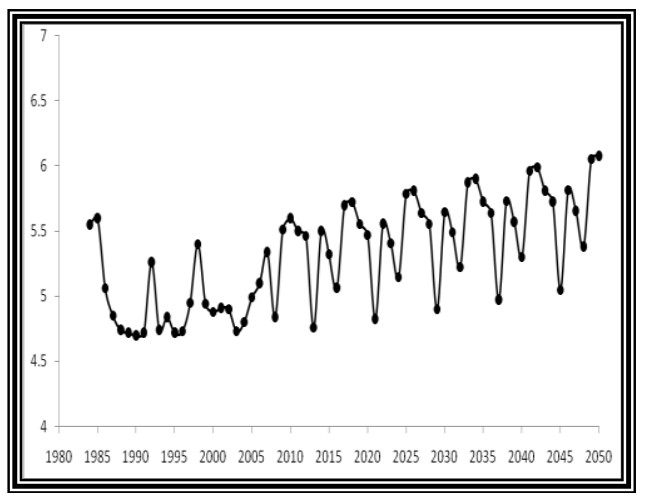

Figure 2: Temporal variation of DO real time data (1984-2015) and forecast data (2016-2050) during monsoon at Sagar South

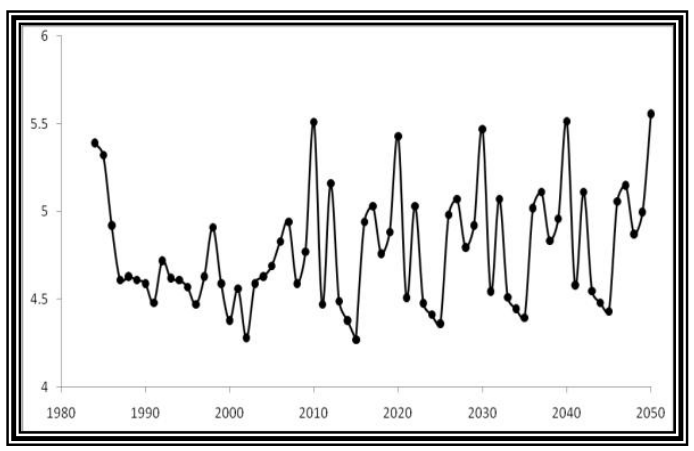

Figure 3: Temporal variation of DO real time data (1984-2015) and forecast data (2016-2050) during postmonsoon at Sagar South
A sharp rise in DO level during premonsoon 2009 in both the stations may be attributed to Aila, a super-cyclone that passed across this World Heritage Site with an approximate speed of $110 \mathrm{~km} / \mathrm{hr}$.

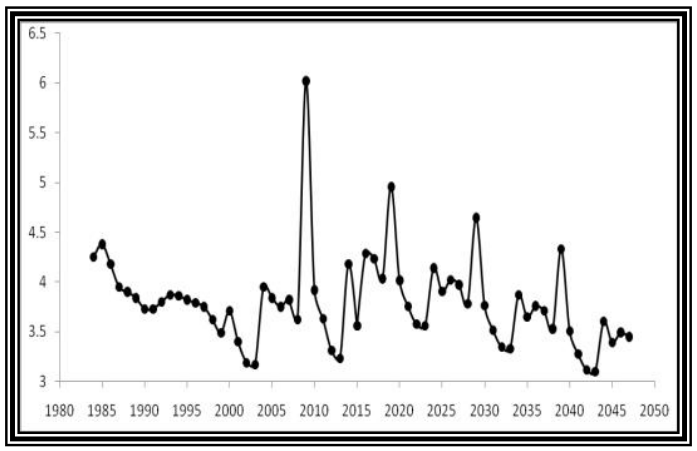

Figure 4: Temporal variation of DO real time data (1984-2015) and forecast data (2016-2050) during premonsoon at Gosaba

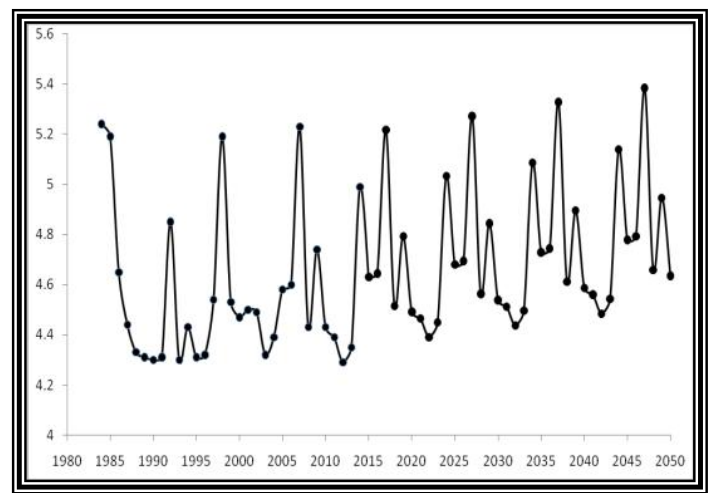

Figure 5: Temporal variation of DO real time data (1984-2015) and forecast data (2016-2050) during monsoon at Gosaba

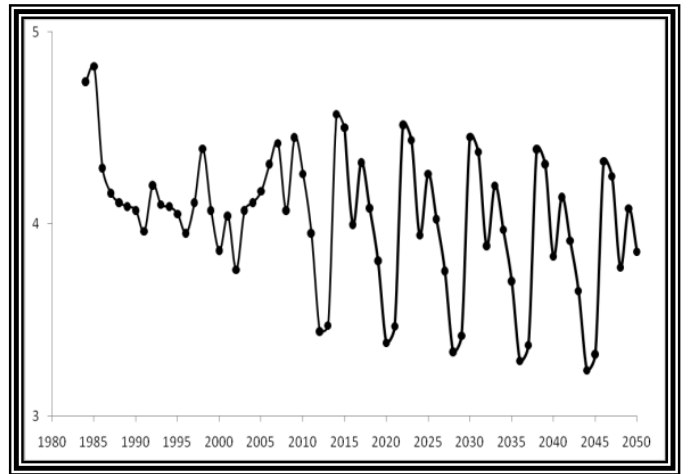

Figure 6: Temporal variation of DO real time data (1984-2015) and forecast data (2016-2050) during postmonsoon at Gosaba

\section{DISCUSSION}

The data sets since 1984-2015 reflect a gradual decrease of DO in both the stations. The rate of decrease is, however, more in the central Indian Sundarbans in and around the station Gosaba $\left(22^{\circ} 08^{\prime} 53.66^{\prime \prime} \quad\right.$ N; 88 $88^{\circ} 34.20^{\prime \prime} \quad$ E) compared to Sagar South $\left(21^{\circ} 38^{\prime} 51.55^{\prime \prime}\right.$ N; 88 02'20.97" E) located in the western Indian Sundarbans. This may be attributed to high salinity in the central Indian Sundarbans due to complete blockage of fresh water in the region (Mitra, 2013; Sengupta et al., 2013; Mitra and Zaman, 
2014; Mitra and Zaman, 2015; Mitra and Zaman, 2016). The siltation of Bidyadhari channel since late $15^{\text {th }}$ century is the primary cause of blockage of fresh water supply in the Matla estuary of the central Indian Sundarbans (Chaudhuri and Chowdhury, 1994). The relatively higher DO value in and around the water of Sagar South in the western Indian Sundarbans is the effect of freshwater supply from Farakka Bararage, which was constructed in 1975 to augment the freshwater supply in the Hooghly estuary in order to ensure the depth of the estuary for navigational purpose (Mitra and Zaman, 2014; Mitra and Zaman, 2015). The long history of gradual oxygen depletion and forecast values has important implications. The water of Indian Sundarbans is already polluted with organic matter generated from shrimp farms, brick kilns, sewage from highly urbanized cities of Kolkata, Howrah and Haldia port-cum-industrial complex, which are directly responsible for lowering the DO value in the system. Such activities such as discharge of significant quantity of additional oxygen demanding substances will worsen the system and have high probability to alter the ecological health of Indian Sundarbans. The importance of adequate circulation coupled with increase of dilution factor (by inter-linking Hooghly and Matla estuaries) must be emphasized in planning process for restoring the aquatic ecosystem in this World Heritage site.

\section{REFERENCES}

1. Baden, S.P., Pihl, L. and Rosenberg, R. (1990) Effects of oxygen depletion on the ecology, blood physiology and fishery of the Norway lobster Nephrops norvegicus. Marine Ecology Progress Series, 67, 151-155.

2. Banerjee, K., Mitra, A. and Bhattacharyya, D.P. (2003) Phytopigment level of the aquatic subsystem of Indian Sundarbans at the apex of Bay of Bengal. Sea Explorers, 6, 39-46.

3. Banerjee, K., Mitra, A., Bhattacharyya, D.P. and Choudhury, A. (2002) Role of nutrients on phytoplankton diversity in the northeast coast of the Bay of Bengal. In Ecology and Ethology of Aquatic Biota; (ed. Arvind Kumar), Daya Publishing House, pp. 102-109.

4. Banerjee, K., Sengupta, K., Raha, A.K. and Mitra, A. (2013) Salinity based allometric equations for biomass estimation of Sundarban mangroves. Biomass \& Bioenergy, (ELSEVIER), 56, $382-391$.

5. Chakraborty, S.K. and Choudhury, A. (1985) Distribution of fiddler crabs in Sundarbans mangrove estuarine complex, India. Proceedings of National Symposium on Biology, Utilization and Conservation of Mangroves, 467-472.

6. Chaudhuri, A.B. and Choudhury, A. (1994) Mangroves of the Sundarbans. Volume I: India, IUCN - The World Conservation Union, pp. 165

7. Diaz, R.J. and Rosenberg, R. (1995) Marine benthic hypoxia: A review of its ecological effects and the behavioural responses of benthic macrofauna. Oceanography and Marine Biology Annual Review, 33, 245-303.

8. Mitra, A. and Choudhury, A. (1994) Dissolved trace metals in surface waters around Sagar Island, India. Journal of Eco-biology, $6(2), 135-139$.

9. Mitra, A. and Zaman, S. (2014) Carbon Sequestration by Coastal Floral Community; published by The Energy and Resources Institute (TERI) TERI Press, India; Copyright The Energy and Resources Institute; ISBN- 978-81-7993-551-4; 2014.

10. Mitra, A. and Zaman, S. (2015) Blue Carbon Reservoir of the Blue Planet. Published by Springer; ISBN 978-81-322-2106-7 (Springer DOI 10.1007/978-81-322-2107-4).

11. Mitra, A. and Zaman, S. (2016) Basics of Marine and Estuarine Ecology, (In press).
12. Mitra, A. In: Sensitivity of Mangrove ecosystem to changing Climate. Springer DOI: 10.1007/978-; 2013, 81-322-1509-7, 323.

13. Mitra, A., Choudhury, A. and Zamaddar, Y.A. (1992) Seasonal Variations in Metal content in the Gastropod Cerithidea (Cerithideopsis) cingulata. Procedure of Zoological Society, Calcutta, 45, 497 - 500 .

14. Mitra, A., Gangopadhyay, A., Dube, A., Andre, C.K.S. and Banerjee, K. (2009) Observed changes in water mass properties in the Indian Sundarbans (Northwestern Bay of Bengal) during 1980 2007. Current Science, 97 (100), 1445-1452.

15. Mitra, A., Ghosh, P.B. and Choudhury, A. (1987) A marine bivalve Crassostrea cucullata can be used as an indicator species of marine pollution. Proceedings of National Seminar on Estuarine Management, 177-180.

16. Mondal, K., Mukhopadhyay, S.K., Biswas, H., De, T.K. and Jana, T.K. (2006) Fluxes of nutrients from the tropical River Hooghly at the land-ocean boundary of Sundarbans, NE Coast of Bay of Bengal, India. Journal of Marine System, 62, 9-21.

17. Saha, S.B., Mitra, A., Bhattacharyya, S.B. and Choudhury, A. (1999) Heavy metal pollution in Jagannath canal, an important tidal waterbody of the north Sundarbans aquatic ecosystem of West Bengal. Indian Journal of Environmental Protection, 19 (11), 801804.

18. Sengupta, K., Roy Chowdhury, M., Bhattacharyya, S.B., Raha, A.K., Zaman, S. and Mitra, A. (2013) Spatial variation of stored carbon in Avicennia alba of Indian Sundarbans. Discovery Nature, (ISSN: 2319-5703), 3 (8), 19 -24.

19. Zaitsev, Y.P. (1993) Impacts of eutrophication on the Black Sea fauna. In: Fisheries and environment studies in the Black Sea system. Rome: United Nations, Food and Agricultural Organization, pp. 64-86. 